\title{
A Randomized Controlled Trial of a Mentalization-Based Intervention (MBT-FACTS) for Families of People with Borderline Personality Disorder
}

Anthony Bateman*, Anna Freud National Centre for Children and Families, 12 Maresfield Gardens, London NW3 5SU, UK. Email: anthony.bateman@ucl.ac.uk

Peter Fonagy, Research Department of Clinical, Educational and Health Psychology, University College London, 1-19 Torrington Place, London WC1E 7HB, UK. Email: p.fonagy@ucl.ac.uk

* Corresponding author 


\begin{abstract}
This paper reports a delayed-treatment randomized controlled trial of a mentalization-based intervention for families or significant others living with or supporting a person with borderline personality disorder (BPD). Fifty-six family members/significant others living with/supporting people with a diagnosis of BPD were randomized either to immediate Families and Carers Training Support (MBT-FACTS), a supportive and skills-based program consisting of five 1.5- to 2-hour evening meetings, delivered by trained family members, or to delayed intervention. The primary outcome was adverse incidents reported by the family member in relation to the person with BPD. Secondary outcomes included self-reported family wellbeing, empowerment, burden, and levels of anxiety and depression. Family members randomized to immediate intervention showed a significant reduction in reported adverse incidents between themselves and the identified patient in the second phase of treatment compared with those randomized to delayed intervention. Analysis of the rate of change indicated a significantly steeper decline for the immediate-treatment group compared with the delayed-intervention group $(\beta=-1.07,95 \%$ CI $[-1.40,-0.74], z=-6.3, p<.000)$. Secondary outcome measures showed family functioning and wellbeing improved more in the immediate-treatment group; changes were maintained at follow-up. There were no differences in depression, total anxiety, and total burden; both groups showed improvement on all these measures. Findings show that the MBT-FACTS program delivered by families to families supporting a person with BPD reduces reported adverse incidents within the family. Further studies are needed to show whether this reduction improves outcomes for the individual with BPD.
\end{abstract}

Keywords: Mentalizing, borderline personality disorder, families, training, support. 


\section{A Randomized Controlled Trial of a Mentalization-Based Intervention (MBT-FACTS) for Families of People with Borderline Personality Disorder}

Borderline personality disorder (BPD) is a common (Torgersen, Kringlen, \& Cramer, 2001) and serious mental illness characterized by pervasive instability in moods, volatile interpersonal relationships, poor self-image, and self-destructive behaviors including suicide attempts and self-harm (Lieb, Zanarini, Schmahl, Linehan, \& Bohus, 2004). The disorder disrupts family, school, and work life, long-term planning, and an individual's developing sense of self-identity. There are effective treatments for BPD (Cristea et al., 2017). However, little emphasis is given to the effect BPD may have on family members of individuals diagnosed with the disorder and how they can support treatment and improve outcomes; this is despite research having shown that families influence treatment outcomes in a range of mental health conditions (Leff \& Vaughn, 1985). In BPD specifically, support for families is recommended in national guidelines (National Institute for Health and Clinical Excellence, 2009).

Families of people with BPD report high levels of distress (Goldman, D'Angelo, \& DeMaso, 1993; Scheirs \& Bok, 2007), strained family relationships (Giffin, 2008), feeling too traumatized and disempowered to be of help to their significant other (Porr, 2010), and higher levels of burden and grief than carers of patients with other severe mental health disorders (Bailey \& Grenyer, 2014). In a focus group run by Dunne and Rogers (2013), family members of individuals with BPD reported that they were overlooked, and even "snubbed" by mental health professionals. They had had to research the diagnosis for themselves using books and websites, and expressed a wish to be better informed about how to effectively manage situations that arose with their loved ones. Crawford et al. (2007) reported that service users with BPD felt that their carers needed more support and 
information about their condition from experts, especially as stigma and misinformation are plentiful. Indeed, in some models of BPD, family members can be understood as implicitly implicated as part of a causal pathway leading to the disorder. Inevitably, this increases family distress. Regardless of this issue, there can be no doubt that an emotionally volatile home environment is likely to worsen the course of the disorder and will compromise treatment outcomes.

Cohort studies of family support programs for BPD have suggested that these programs improve family functioning and reduce burden. The Family Connections program, delivered by family members with support from professionals, offers psychoeducation, problem solving, family relationship skills, and a support network over 12 weekly sessions (Hoffman, Fruzzetti, \& Buteau, 2007; Hoffman et al., 2005). This is a major commitment in terms of time for families trying to get on with their own lives. Improvements were noted in symptom distress, subjective sense of coping, and decreased burden. Staying Connected when Emotions Run High, reported by Pearce et al. (2017), is a briefer intervention delivered by professionals offering five sessions on core principles of self-care, keeping calm in distress, setting boundaries, nondirective counselling skills, and safety planning. Again, families reported less burden, better sense of wellbeing, and improved quality of life. In a recent pre-post assessment study of an intervention for families with young people with BPD facilitated by clinicians, Making Sense of BPD, three 2-hour sessions, conducted over 3 consecutive weeks, were offered, covering the features of personality disorder, diagnosis, causes, treatment, interpersonal skills, relationship patterns, and self-care (Pearce et al., 2017). These topics were discussed within a youth developmental context, and a family member with lived experience contributed to the final session. Participants showed decreased subjective burden but increased objective burden and no change in distress. Knowledge of personality disorder increased. Other family interventions delivered primarily by 
professionals are well described but remain unevaluated (Gunderson, Berkowitz, \& RuizSancho, 1997). Overall, in pre-post studies the impact of family support interventions has been largely positive on the family. Interventions that are more focused on the emotional impact of BPD on the family have been consistently associated with benefit and may be more useful than more limited educational interventions. Families, who were integral to developing the brief mentalization-based families and carers training support program (MBT-FACTS) described in this paper, were given all the information about family programmes. They wanted a brief program of no more than five sessions that was focused less on psychoeducation and more on developing skills for managing their interactions with their family member with BPD. Further, they were clear that families should deliver the program and the involvement of mental health professionals should be limited. All these factors were taken into account in developing MBT-FACTS, particularly the concern that the program should be deliverable by family members themselves having received limited initial training. Across a number of diagnostic conditions there have increasingly been initiatives to engage experts by experience in the delivery of family support programs, in preference to professionals, for pragmatic, financial, and ethical reasons. A 12-week Family-to-Family Education Program (FTF) for family members of adults with mental illness, run by the National Alliance on Mental Illness, showed that a family-led structure is feasible and can be successful (Dixon et al., 2011). In a delayed-treatment RCT, FTF participants, family members of someone with a mental health problem, had significantly greater improvements in problem-focused coping as measured by empowerment and illness knowledge, and significantly enhanced emotion-focused coping as measured by increased acceptance of their family member's illness, as well as reduced distress and improved problem solving. Subjective illness burden did not differ between groups. Improvements were sustained at 6- 
month follow-up (Lucksted et al., 2013). There was no information about the effects on family interactions or patient outcomes.

This paper reports on a delayed-treatment RCT of MBT-FACTS, a brief families and carers training support program based on principles of mentalizing (Bateman \& Fonagy, 2016), for families and others living or closely involved with a person with BPD. The intervention was delivered by families trained in the program. While previous studies have shown that educational interventions for families based on various treatment models of BPD can reduce distress in the family, no previous study, to our knowledge, has shown that these interventions have also led to a reduction of difficulties for the patient in the family/relational context using a comparison group. In the present investigation we set ourselves a goal of establishing whether an educational and skills program focused on the mentalizing model of BPD increases interpersonal understanding in the family and consequently achieves a reduction of critical incidents reported by the family. This randomized trial of family psychoeducation and skill development identified the diarized reports of family crisis events as its pre-declared primary outcome.

Within the theoretical model of mentalization-based treatment (MBT), the acquisition of agency — seeing action as being motivated by mental states - is taken to be the vital ingredient for improvement. The educational program we designed had at its core the provision of a comprehensive account of family interaction from the point of view of the designated patient, with some associated relational skills. However, the MBT model also suggests that self-experience being understood by others is essential for learning and change, as well as being able to see things from others' perspective. Just as the person with BPD needs to feel understood by others (e.g., family members and clinicians), so family members similarly require their own experience in relation to the problems presented by the family member to be appreciated. We therefore assumed that the MBT perspective would be more 
effectively communicated by an educator who was also seen to be someone struggling with the challenges of being a family member of a person with the diagnosis of BPD in their own home. Fonagy, Luyten, Allison, and Campbell (2017a, 2017b) have outlined a developmental model that may explain why, everything else being equal, a teacher who is also a family member would be better able to communicate the principles of MBT than an "expert". We hypothesized that the communicator who is also seen as understanding the challenges faced by the family would be most likely to achieve change. In keeping with intervention protocols we have designed in the past, our interest was also in part to establish a relatively low-cost educational intervention. With these aims in mind, we trained family members in the MBT educational curriculum and requested them to deliver the group family training.

\section{Method}

\section{Design}

This was a delayed-treatment RCT conducted at the Anna Freud National Centre for Children and Families, London, UK. The trial was registered in the ISRCTN registry (registration number ISRCTN39303837). Ethical approval was obtained from the National Health Service Health Research Authority Research Ethics Committee (reference 14/LO/1519). Participants were provided with written information and consented only after receiving a complete description and discussion of the study.

\section{Participants}

Eligible participants were adults aged over 18 living with or supporting a child, parent, sibling, partner, or other family member or significant other with a clinical diagnosis of BPD. Participants were recruited from local services where the designated family member or significant other was receiving attention. Services contacted included personality disorder 
clinics, Child and Adolescent Mental Health Services, user groups, family organizations, and voluntary services. Reimbursement for travel expenses was offered to participants but there was no other inducement for participation. All families with a family member aged over 14 years and under 65 years with a formal diagnosis of BPD were invited to participate.

Exclusion criteria were kept to a minimum: Families and significant others who were not fluent in English, or had a co-occurring diagnosis of schizophrenia or schizoaffective disorder or active psychosis or severe substance addiction requiring specialist intervention were not accepted.

A total of 66 participants were recruited, 10 of whom were excluded (Figure 1). Five people did not meet inclusion criteria, two declined to participate once the trial had been explained to them because a family group-based intervention was not acceptable to them, and three gave other reasons for declining the offer of the intervention (the time of the meetings, travel problems, and illness), leaving 56 people who were randomized. Three participants dropped out post-randomization, but are included in the intent-to-treat model because baseline data were collected prior to randomization. Of the 56 family members, 37 were parents (22 mothers, 15 fathers), 16 were partners, 2 were siblings, and 1 was an unrelated next of kin of the person with BPD. Baseline characteristics of the total sample are summarized in Table 1. Groups did not differ significantly in terms of any of the demographic or clinical variables. As might be expected, the patient population indirectly involved in the study was relatively young and surprisingly less dominated by female gender than might be expected. The mean age of the person identified with BPD in the immediatetreatment group was 21 years and in the delayed-treatment group 23 years; $58 \%$ and $62 \%$ were female, respectively. 


\section{Randomization}

Randomization was carried out independently at University College London using a stochastic minimization program (MINIM) following the collection of baseline data. Randomization was stratified according to gender and age (under and over 45 years of age).

Families with a first-degree relative or significant other in close contact with the person with the diagnosis of BPD were randomized to immediate treatment with a maximum of 5 weeks' wait or to a comparison group offered the same package on average 9 weeks after the collection of baseline data and consent for randomization. Allocation ratio was 1:1. The primary outcome of reported incidents in the family related to symptoms of BPD was recorded by participants daily and collected from them at weekly intervals. Self-report questionnaires were completed weekly.

Participants provided follow-up data for up to 12 weeks after completion of the intervention. As the trial was a delayed-treatment trial, comparison with the control group was available for only approximately 3 weeks after the termination of the intervention. Following the intervention, both groups were followed up to establish maintenance of treatment effect.

\section{Intervention: Family and Carers Training Support (MBT-FACTS)}

The MBT-FACTS program teaches the families and significant others of individuals with BPD basic information about the disorder and trains them in simple, safe skills to help them manage and respond to some of the common problems they may encounter with the person with BPD. The educational program and the interventions proposed were informed by MBT for BPD and incorporated a psychoeducation component along with coping skills enhancement using some strategies adopted from the MBT manual (Bateman \& Fonagy, 2016), including understanding typical manifestations of BPD as indications of inadequate 
mentalizing, along with typical responses to such behaviors as equally reflecting a failure to achieve effective mentalizing of the problem. The implications of the impact of family conflict on mentalizing and the desirability of avoiding ineffective mentalizing interactions provided the rationale for the approach. Following the principles of collaboration and shared decision making that MBT embodies, the content of the program was developed jointly with interested families and professionals, building on current work at the Anna Freud National Centre for Children and Families to train mental health professionals in the treatment of BPD. Two family members participated in designing the manual and were trained to deliver a pilot course. Eighteen families were recruited to participate in the pilot course. The pilot course was found to be acceptable and the trainers were observed to be able to deliver the manualized package according to protocol. A research psychologist rated video of the delivery of each module against the content and skills defined in the protocol. In addition each participant in the pilot course was interviewed after each module to assess their acquisition of understanding of the topic. Any areas of misunderstanding were reformulated and the manual was rewritten as needed. Participants' comments and suggestions were used to review each module and to make changes. All participants were eligible to become trainers; volunteers were asked to commit to being trained and to deliver a minimum of two full programs. There were no other eligibility requirements. Four family members who were graduates of this program were recruited to deliver the program evaluated in the trial.

Training of the family members for the trial was delivered in two evening sessions of 2 hours each, using didactic teaching, going through the information sheets that form part of the course materials, using a specified slide set, practicing role plays, watching video clips about BPD, and discussing their own experiences. Following the two evenings all family trainers were given the complete package of slides, information sheets for presenters and participants, and exercise books to be given to participants for home use. 
MBT-FACTS is delivered over five evening sessions lasting either 1 hour (session 1) or 1.5 hours (sessions $2-5$ ). The program covers five topics:

1. Introduction; What is BPD?: This includes discussion of the descriptive characteristics of BPD and identification of the main problem areas the families experience during interaction with the person with BPD.

2. Mindfulness and Mentalizing: In this session there is discussion of the two concepts, and practice of mindfulness techniques to help manage family members' emotional reactivity and mentalizing talk in interpersonal process.

3. Mentalizing: This session involves role plays based on the problems being experienced by the families.

4. Mentalizing and Empathic Validation: This includes work on developing the capacity to see things from the other person's perspective.

5. Problem Solving and Review: In this final session, the use of mentalizing techniques to enhance basic problem-solving is discussed.

Each session comprises a mixture of didactic presentations, small-group work, role play, watching video clips, and general discussion. The materials are available online at https://www.annafreud.org/training/mentalization-based-treatment-training/families-andcarers-training-and-support-programme-facts/. Each evening session was attended by between 8 and 11 participants. The course had a 90\% attendance rate. The program was delivered six times, three times for the immediate-intervention group and three times for the delayed-intervention group.

Adherence to delivery of the MBT-FACTS program was assessed by interviews with the family trainer each week using a checklist, which asked about (a) delivery of key points of knowledge contained in the module delivered that week, (b) the use of specified role plays 
for skill development, (c) engagement of participants in discussion, and (d) practice of skills from earlier modules. Adherence was considered acceptable if $60 \%$ of the key points of the module were delivered, $66 \%$ of the specified role plays were undertaken, and one skill from a previous module was practiced.

\section{Measures}

\section{Primary outcome measure}

The primary outcome was the number of adverse incidents involving the person with BPD reported by the family member.

All participants completed daily incident diaries 7 days prior to and daily during the 5-week program, describing any predefined problematic interactions that had occurred with their family member/significant other with BPD. Participants were trained in the use of the measure, which required the recording and brief description of "critical events". These were defined as symptomatic or relational manifestations of BPD, including self-harm, suicidal threats, physical fights, explosive or aggressive verbal arguments, and withdrawal and refusal to interact (e.g. the person with BPD shutting themselves into a bedroom for days).

Participants were asked to record each event on a specially designed event report sheet on the day it occurred, noting the individuals involved in the event, the circumstances preceding the event, and the outcomes of it. Records of incidents were collected by an objective assessor blind to intervention allocation.

Participants found it challenging to adhere to the intended reporting schedule; daily record sheets where no incidents happened were completed only rarely and several events covering a number of days were recorded in single record sheets. Therefore, the frequency of the events was summed for 7-day periods and, for the purposes of analysis and reporting, further aggregated for the baseline period of at least 7 days, the initial 3-week phase of the 
intervention, the second phase of the intervention, and a 3-week follow-up phase, and expressed as mean number of incidents per week. This procedure yielded relatively robust indications of incidents occurring during various phases of the study. The follow-up phase reported is restricted to 3 weeks because data from the delayed treatment group were available only for this period for the entire sample (after which the comparison group entered the intervention). Full follow-up data are available for the entire sample of the immediate treatment group for comparison of end of intervention and follow-up points. During the extended follow-up period (12 weeks), data collection from participants continued weekly, but many discontinued regular reporting.

\section{Secondary outcome measures}

Participants completed a weekly battery of self-report measures focusing on their wellbeing prior to treatment, during the intervention, and over follow-up of 3 months. Symptom measures covered depression (the Beck Depression Inventory; Beck, Ward, Mendelson, Mock, \& Erbaugh, 1961) and anxiety (the Spielberger State-Trait Anxiety Inventory; Spielberger, Gorsuch, \& Lushene, 1970). Family burden was assessed using the Burden Assessment Scale (Reinhard, Gubman, Horwitz, \& Minsky, 1994). This measure consists of 19 items and has excellent reliability. Studies show the scale has a stable factor structure whether it is self- or interviewer-administered (Ivarsson, Sidenvall, \& Carlsson, 2004). The scale differentiates between family samples with different levels of burden, is sensitive to changes over time, and gives a total score of family burden with indication of subjective and objective burden. The total score of family burden was used. The WarwickEdinburgh Mental Well-Being Scale (Tennant et al., 2007) is a 14-item scale with 5 response categories; responses are summed to provide a single score ranging from 14 to 70 . The items are all worded positively and cover both feeling and functioning aspects of mental wellbeing. 
Family function was assessed using the SCORE-15 index of family function and change (Stratton, Bland, Janes, \& Lask, 2010) and the Family Empowerment Scale (FES; Koren, Dechillo, \& Friesen, 1992). The SCORE-15 generates a total score using 15 Likert-scale items, which record perceptions of the family about problems within the family. The FES is based on a two-dimensional conceptual framework of empowerment derived from the literature. One dimension reflects empowerment with respect to the family, service system, and larger community and political environment; the other dimension reflects the expression of empowerment as attitudes, knowledge, and behaviors. The overall score was used.

Data were collected electronically via the POD (Patient Owned Data) self-report internet-based data collection system, which enables participants to complete self-report measures on any internet-enabled device (e.g.., smartphone, tablet, or computer). Data are recorded and are immediately accessible to administrators with information about the time of completion and automatic scoring. Participants completed the measures at home or on devices available at the Anna Freud National Centre for Children and Families. The software enables participants to monitor their own scored data graphically. Participants completed the measures at baseline, weekly for 6 weeks during the intervention phase, and then biweekly during the extended follow-up. As with the primary outcome measure, comparison between the two groups was available only for the first 3 weeks of the 12-week follow-up period.

\section{Analyses}

The primary outcome was aggregated for 3-weekly periods as the average number of incidents per week. Event frequency is often best modeled using the Poisson distribution. The aggregated measure of weekly average incidents gave a normally distributed estimate for average weekly frequency of incidents, so a linear regression model was used with fixed effects for age, gender, group (immediate intervention versus delayed intervention) and time 
(baseline $=0,3$ weeks $=1,6$ weeks $=2$, follow-up $=3$ ) and the interaction of group and time and random effects for intercept and slope, assuming unstructured covariance between the random effects. Linear mixed-effects models were used to test intervention differences at the 3-weekly phases (3 weeks and 6 weeks of intervention and follow-up).

Questionnaire data were similarly modeled except for the time variable, which was estimated using seven time points (baseline, weekly observations for 6 weeks, and at the follow-up point) using linear mixed-effects models. Outcomes were evaluated in terms of the rate of change in the self-reported measures in the immediate- and delayed-treatment groups based on the mixed-effects models, which included participant and time of assessment as random effects. We predicted more rapid changes in the desirable directions for participants in the immediate-treatment group. Treatment effects were also evaluated at each observed time point based on the modelled marginal estimates.

The statistical package STATA 14.1 ME was used to estimate the mixed-effects models. Overall, $6 \%$ of data were missing in the primary outcome variable and slightly more in the self-report measures. All available observations were included in the models. Missing data were assumed to be at random and did not correlate with any other variable collected.

\section{Results}

\section{Primary Outcome}

The mean numbers of reported incidents by participants in the immediate- and delayed-treatment groups are shown in Table 2. The mixed-effects model using random intercepts and slope showed that predicted differences were statistically significant both at the second phase of treatment and immediately post-treatment (See Table 2).

Neither of the main effects of group or time were statistically significant. The analysis of the rate of change indicated a significantly steeper decline for the immediate-treatment 
group compared with the delayed-intervention group $(\beta=-1.07,95 \% \mathrm{CI}[-1.40,-0.74], z=-$ $6.3, \mathrm{p}<.000$ ) (see Figure 2). In the immediate-treatment group, incidents declined in frequency from Phase 1 and the estimated marginal mean frequencies were significantly lower by phase 2 and remained lower post-treatment.

\section{Secondary Outcomes}

Table 3 displays the marginal means from the mixed-effects models. Family empowerment was best fitted by a linear model, which suggested a significant increase in empowerment in the immediate treatment group relative to delayed treatment $(\beta=2.21,95 \%$ CI [1.32, 3.09], $z=4.98, p<.0001)$. While the overall increase in empowerment was significant, the differences at each time point in the estimated marginal means only approached significance at follow-up (difference estimate $=9.41,95 \%$ CI $[-0.41,19.24], z=$ $1.88, p=.06)$.

The SCORE-15, which measures family problems, declined significantly more rapidly for the immediate-treatment group $(\beta=-1.21,95 \% \mathrm{CI}[-2.07,-0.33], z=-2.72, p<$ .007). Differences in family function appeared from the first week in treatment (difference estimate $=-4.62,95 \% \mathrm{CI}[-9.18,-0.08], z=-2.00, p=.046)$. The difference increased gradually throughout the study, with a difference of 10 points on follow-up (difference estimate $=-10.65,95 \%$ CI $[-16.31,-4.99], z=-3.69, p=.0003)$.

The decline in anxiety reported by the family members over the course of the intervention was somewhat more rapid for the immediate-intervention group $(\beta=-0.90,95 \%$ CI $[-1.65,-0.15], z=2.36, p<.02)$. Notwithstanding the steeper decline, at no time point were the two groups significantly different in the estimated mean level of self-reported anxiety. 
There was a marginal improvement in sense of wellbeing over the course of the study in the immediate-treatment group compared with the delayed-intervention group $(\beta=0.88$, $95 \% \mathrm{CI}[-0.15,1.61], z=2.35, p<.02)$. In line with this improvement, wellbeing was significantly higher in the immediate-intervention group compared with the delayedintervention group at end of treatment (difference estimate $=5.74,95 \%$ CI $[0.10,11.39], z=$ $1.99, p=.046$ ). At follow-up there was a slight increase (difference estimate $=6.66,95 \% \mathrm{CI}$ $[0.45,12.78], z=2.11, p=0.035)$.

The decline in self-rated depression scores was also greater in the immediateintervention group compared with the delayed-intervention group $(\beta=-0.74,95 \%$ CI $[-1.33$, $-0.14], z=2.43, p<.015)$. This model included a quadratic component for time because the reduction in both groups was very rapid during the first phase of treatment. However, the differences in favor of the immediate-treatment group were not statistically significantly lower even at the follow-up point (difference estimate $=-4.55,95 \%$ CI $[-9.53,0.43], z=$ $1.79, p=0.73)$.

There was a significant decline in burden across both groups, following both a linear $(\beta=3.36,95 \% \mathrm{CI}[-4.67,-2.06], z=-5.03, p=.00001)$ and quadratic $(\beta=0.37,95 \% \mathrm{CI}$ $[0.19,0.53], z=3.97, p=.00001)$ trend. However, at no time point did the two groups significantly differ in the mean level of burden reported.

\section{Discussion}

This is the first RCT of a family educational and skills-based program delivered by family members of someone with BPD to other family members or significant others. The pre-declared primary outcome was adverse incidents reported by the family member in relation to the person with BPD. The reported incidents were primarily related to intrafamilial interactions, and included incidents such as physical violence or violent arguments, 
threatening suicide, conflicts about self-harm behaviors, behavior perceived as asocial or antisocial (e.g., individuals with BPD locking themselves in their rooms), or uncontrolled emotional outbursts. Such incidents declined significantly in the families randomized to the immediate-intervention group compared with those randomized to delayed intervention. The size of the effect was substantial (pre-post comparison $d=1.71,95 \%$ CI $[0.96,2.46]$; group comparison at follow-up $d=1.9,95 \%$ CI $[1.16,2.57])$.

In addition, participants in the immediate-intervention group showed better functioning within the family by the end of the first phase of treatment and experienced more empowerment and sense of wellbeing by the end of treatment than those in the control group. Self-reported levels of anxiety and depression in family members declined more rapidly in the immediate-intervention group. Of note, both groups reported a rapid and substantial decline in overall burden of their family member/significant other's illness, suggesting that such relief was more likely to be attributable to simply becoming involved in the study and being able to share the burden with the research staff, rather than to the intervention itself.

The reduction in reported adverse incidents is an important finding as it may reflect improved understanding by family members of the person with BPD. Such an improvement might in turn impact positively on the ability of the person with BPD to use the services with which they are involved. Alternatively, the reduction of incidents reported by families could reflect a change of attitude to such events. It is possible that following the training they experience fewer events as adverse, that is, they became more tolerant of such incidents and so report them less frequently. A change of criterion of what may be worth reporting could also have occurred, reflecting exposure to other families as part of the group experience. Some of the families may have reported very serious incidents that made other family members reconsider the seriousness of the experiences they had initially felt it was important to report. Even if family members simply reported fewer incidents without an actual change 
in the behavior of the individually with BPD, the family members were reporting less depression and anxiety and appeared to feel more empowered.

We should note, however, that even if they were less acutely distressed following the intervention, family members still reported feeling significantly burdened by the condition of the person with BPD. It seems that understanding the person with BPD and feeling understood by others in a similar predicament increased family members' wellbeing, improved their mood, and reduced reported adverse incidents, but did not remove the experience of burden, despite the apparent initial relief of sharing the problems with researchers. It may be that the act of sharing legitimizes the pressure the family feels. This leaves open the question of why increased mentalizing of the individual with BPD and of the family member's reactions to interactions with that individual did not reduce the burden further. We can speculate that while perhaps the family feel more empowered and the tensions in the family are reduced because of a more mentalizing atmosphere, the newly acquired task of mentalizing is itself hard work and quite burdensome. Understanding others' perspectives and monitoring being and feeling understood is an obligation. So, while outcome studies show that it may contribute to alleviating depression and anxiety (Bateman \& Fonagy, 2009, 2013) and improve family function (Rossouw \& Fonagy, 2012) the increased sense of agency may leave a person with an increased sense of responsibility. These findings on illness-related burden are in contrast to previous uncontrolled studies of interventions not focused on mentalizing (Hoffman et al., 2007; Hoffman et al., 2005; Martino et al., 2014), which attributed the reduction in burden to the intervention. It is possible that in these studies, too, the sharing of experience and the relief derived from being involved in a study was critical, although Pearce et al. (2017) found that the objective burden remained unchanged despite sharing. Further controlled studies may be needed to show whether the changes in family burden reported can be attributed to the intervention. 
Importantly, this study suggests that delivery of a brief structured family intervention based on mentalizing principles by families with limited levels of training from professionals is feasible at low cost. Community-based, free, peer-to-peer programs complement services offered within the professional mental health system, and peers with lived experience may have a unique voice in delivering such programs (Day et al., 2011). From a mentalizing perspective, if family members feel mentalized - that is, they experience that their concerns and emotional states have been accurately reflected from their perspective by another person whom they see as facing similar problems - this may allow family members to continue mentalizing despite stressful circumstances, especially in situations that have the potential to activate attachment processes powerfully.

\section{Limitations}

There are a number of limitations to this study despite the attempt to implement RCT methodology. First, there was no direct information from the patients themselves, and we do not know whether they experienced any benefit from the intervention. Ethical approval did not allow collection of these data for the study. Future studies will have to gather data from the person being cared for as well as the carers. This will provide the patient's perspective and indicate beneficial or harmful effects of the intervention on treatment, as well as being a more robust finding about changes in family function. Again, the simple fact of collecting such information may have benefits for the patient.

Second, families being supported to give support are probably more likely to report benefits, and so there is substantial potential for bias in reporting. The significant reduction in incidents from families offered support immediately compared with those who had to wait might be due simply to feeling the burden of attending a program and feeling further burdened by the reporting of incidents, rather than an actual reduction (although an 
independent rater attempted to check each report with the family member when it was submitted).

Third, the cross-over design did not allow long-term follow-up of group differences and we can only claim that improvements appeared to have been maintained beyond the end of treatment. In a fully randomized design differences between the two groups may not have been retained in the longer term. There have been no studies of family-based support interventions with substantial follow-up periods. More positively, the cross-sectional design used in this study provides a built-in replicability, and the findings show that the delayed treatment group also benefitted from the intervention.

Fourth, the study is based on self-report. There were no direct observations to indicate that the nature of family interactions had changed. It thus remains possible that families simply learned to report interactions as being less concerning rather than to interact more constructively with the individual with BPD.

Finally, if the changes reported in the study are real it remains unclear how they came about. The improvements in adverse incidents may have been related to generic factors; the content of the program may be of lesser importance. There may have been remoralization (Howard, Lueger, Maling, \& Martinovich, 1993), for example, through meeting others, especially in terms of thinking about the relationship with the person with BPD, and so a tendency to minimize continuing problems. Nevertheless, because we have developed a relatively cheap intervention, larger scale multisite studies are now possible. The intervention was well received and is deliverable by families themselves after receiving very little training. In a larger scale trial it would be possible to determine whether the intervention enhances the effectiveness of treatment for the patient and, if so, whether it helps with specific treatment models. This is important, as it is known that current treatments are only moderately effective (Fonagy, Luyten, \& Bateman, 2017). A positive interaction between this 
intervention and an evidence-based treatment will enhance outcomes for people with BPD, which is the aim of their families as well as the professionals who treat them. 


\section{References}

Bailey, R. C., \& Grenyer, B. F. (2014). Supporting a person with personality disorder: A study of carer burden and well-being. Journal of Personality Disorders, 28, 796-809. doi: 10.1521/pedi_2014_28_136

Bateman, A., \& Fonagy, P. (2009). Randomized controlled trial of outpatient mentalizationbased treatment versus structured clinical management for borderline personality disorder. American Journal of Psychiatry, 166, 1355-1364. doi:

10.1176/appi.ajp.2009.09040539

Bateman, A., \& Fonagy, P. (2013). Impact of clinical severity on outcomes of mentalisationbased treatment for borderline personality disorder. British Journal of Psychiatry, 203, 221-227. doi: 10.1192/bjp.bp.112.121129

Bateman, A. W., \& Fonagy, P. (2016). Mentalization-based treatment for personality disorders: A practical guide. Oxford, UK: Oxford University Press.

Beck, A. T., Ward, C. H., Mendelson, M., Mock, J., \& Erbaugh, J. (1961). An inventory for measuring depression. Archives of General Psychiatry, 4, 561-571.

Crawford, M., Rutter, D., Price, K., Weaver, T., Josson, M., Tyrer, P., . . Ryrie, I. (2007). Learning the lessons: a multi-method evaluation of dedicated community-based services for people with personality disorder. Report submitted to the National Coordinating Centre for NHS Service Delivery and Organisation R \& D (NCCSDO). London, UK: Imperial College.

http://www.netscc.ac.uk/hsdr/files/project/SDO_FR_08-1404-083_V01.pdf

Cristea, I. A., Gentili, C., Cotet, C. D., Palomba, D., Barbui, C., \& Cuijpers, P. (2017). Efficacy of psychotherapies for borderline personality disorder: A systematic review and meta-analysis. JAMA Psychiatry, 74, 319-328. doi: 10.1001/jamapsychiatry.2016.4287 
Day, C., Kowalenko, S., Ellis, M., Dawe, S., Harnett, P., \& Scott, S. (2011). The Helping Families Programme: A new parenting intervention for children with severe and persistent conduct problems. Child and Adolescent Mental Health, 16, 167-171. doi: $=10.1111 / \mathrm{j} .1475-3588.2010 .00588 . \mathrm{x}$

Dixon, L. B., Lucksted, A., Medoff, D. R., Burland, J., Stewart, B., Lehman, A. F., . . Murray-Swank, A. (2011). Outcomes of a randomized study of a peer-taught Familyto-Family Education Program for mental illness. Psychiatric Services, 62, 591-597. doi: 10.1176/ps.62.6.pss6206_0591

Dunne, E., \& Rogers, B. (2013). "It's us that have to deal with it seven days a week": Carers and borderline personality disorder. Community Mental Health Journal, 49, 643-648. doi: 10.1007/s10597-012-9556-4

Fonagy, P., Luyten, P., Allison, E., \& Campbell, C. (2017a). What we have changed our minds about: Part 1. Borderline personality disorder as a limitation of resilience. Borderline Personality Disorder and Emotion Dysregulation, 4, 11. doi: 10.1186/s40479-017-0061-9

Fonagy, P., Luyten, P., Allison, E., \& Campbell, C. (2017b). What we have changed our minds about: Part 2. Borderline personality disorder, epistemic trust and the developmental significance of social communication. Borderline Personality Disorder and Emotion Dysregulation, 4, 9. doi: 10.1186/s40479-017-0062-8

Fonagy, P., Luyten, P., \& Bateman, A. (2017). Treating borderline personality disorder with psychotherapy: Where do we go from here? JAMA Psychiatry, 74, 316-317. doi: 10.1001/jamapsychiatry.2016.4302

Giffin, J. (2008). Family experience of borderline personality disorder. Australian and New Zealand Journal of Family Therapy, 29, 133-138. doi: 10.1375/anft.29.3.133 
Goldman, S. J., D'Angelo, E. J., \& DeMaso, D. R. (1993). Psychopathology in the families of children and adolescents with borderline personality disorder. American Journal of Psychiatry, 150, 1832-1835. doi: 10.1176/ajp.150.12.1832

Gunderson, J. G., Berkowitz, C., \& Ruiz-Sancho, A. (1997). Families of borderline patients: A psychoeducational approach. Bulletin of the Menninger Clinic, 61, 446-457.

Hoffman, P. D., Fruzzetti, A. E., \& Buteau, E. (2007). Understanding and engaging families: An education, skills and support program for relatives impacted by borderline personality disorder. Journal of Mental Health, 16, 69-82. doi: $10.1080 / 09638230601182052$

Hoffman, P. D., Fruzzetti, A. E., Buteau, E., Neiditch, E. R., Penney, D., Bruce, M. L., . . Struening, E. (2005). Family Connections: A program for relatives of persons with borderline personality disorder. Family Process, 44, 217-225.

Howard, K. I., Lueger, R. J., Maling, M. S., \& Martinovich, Z. (1993). A phase model of psychotherapy outcome: Causal mediation of change. Journal of Consulting and Clinical Psychology, 61, 678-685.

Ivarsson, A. B., Sidenvall, B., \& Carlsson, M. (2004). The factor structure of the Burden Assessment Scale and the perceived burden of caregivers for individuals with severe mental disorders. Scandinavian Journal of Caring Sciences, 18, 396-401. doi: 10.1111/j.1471-6712.2004.00298.x

Koren, P. E., Dechillo, N., \& Friesen, B. J. (1992). Measuring empowerment in families whose children have emotional disabilities: A brief questionnaire. Rehabilitation Psychology, 37, 305-321. doi: 10.1037/0090-5550.37.4.305

Leff, J. P., \& Vaughn, C. (1985). Expressed emotion in families: Its significance for mental illness. New York, NY: Guilford Press. 
Lieb, K., Zanarini, M. C., Schmahl, C., Linehan, M. M., \& Bohus, M. (2004). Borderline personality disorder. Lancet, 364, 453-461. doi: 10.1016/s0140-6736(04)16770-6

Lucksted, A., Medoff, D., Burland, J., Stewart, B., Fang, L. J., Brown, C., . . . Dixon, L. B. (2013). Sustained outcomes of a peer-taught family education program on mental illness. Acta Psychiatrica Scandinavica, 127, 279-286. doi: 10.1111/j.16000447.2012.01901.x

Martino, F., Lia, L., Bortolotti, B., Menchetti, M., Monari, M., Ridolfi, M. E., . . Berardi, D. (2014). La famiglia del paziente con disturbo borderline di personalita: Carico della malattia e interventi destinati ai caregiver. [The family of a patient with borderline personality disorder: Burden of illness and interventions for caregivers]. Rivista di Psichiatria, 49, 199-206. doi: 10.1708/1668.18258

National Institute for Health and Clinical Excellence. (2009). Borderline personality disorder: Treatment and management. Clinical guideline 78. London, UK: National Institute for Health and Clinical Excellence. http://www.nice.org.uk/guidance/cg78/evidence/cg78-borderline-personality$\underline{\text { disorder-bpd-full-guideline } 3}$

Pearce, J., Jovev, M., Hulbert, C., McKechnie, B., McCutcheon, L., Betts, J., \& Chanen, A. M. (2017). Evaluation of a psychoeducational group intervention for family and friends of youth with borderline personality disorder. Borderline Personality Disorder and Emotional Dysregulation, 4, 5. doi: 10.1186/s40479-017-0056-6

Porr, V. (2010). Overcoming borderline personality disorder: A family guide for healing and change. Oxford, UK: Oxford University Press.

Reinhard, S. C., Gubman, G. D., Horwitz, A. V., \& Minsky, S. (1994). Burden Assessment Scale for families of the seriously mentally ill. Evaluation and Program Planning, 17, 261-269. doi: 10.1016/0149-7189(94)90004-3 
Rossouw, T. I., \& Fonagy, P. (2012). Mentalization-based treatment for self-harm in adolescents: A randomized controlled trial. Journal of the American Academy of Child and Adolescent Psychiatry, 51, 1304-1313. doi: 10.1016/j.jaac.2012.09.018

Scheirs, J. G., \& Bok, S. (2007). Psychological distress in caretakers or relatives of patients with borderline personality disorder. International Journal of Social Psychiatry, 53, 195-203. doi: 10.1177/0020764006074554

Spielberger, C. D., Gorsuch, R. L., \& Lushene, R. E. (1970). The State-Trait Anxiety Inventory (Self-Evaluation Questionnaire). Palo Alto, CA: Consulting Psychologists Press.

Stratton, P., Bland, J., Janes, E., \& Lask, J. (2010). Developing an indicator of family function and a practicable outcome measure for systemic family and couple therapy: The SCORE. Journal of Family Therapy, 32, 232-258. doi: 10.1111/j.14676427.2010.00507.x

Tennant, R., Hiller, L., Fishwick, R., Platt, S., Joseph, S., Weich, S., . . Stewart-Brown, S. (2007). The Warwick-Edinburgh Mental Well-being Scale (WEMWBS): development and UK validation. Health and Quality of Life Outcomes, 5, 63. doi: $10.1186 / 1477-7525-5-63$

Torgersen, S., Kringlen, E., \& Cramer, V. (2001). The prevalence of personality disorders in a community sample. Archives of General Psychiatry, 58, 590-596. doi: 10.1001/archpsyc.58.6.590 
Table 1

Characteristics of Participants in the FACTS Program

\begin{tabular}{|c|c|c|c|c|c|}
\hline & \multicolumn{2}{|c|}{ Immediate Intervention } & \multicolumn{2}{|c|}{ Delayed Intervention } & \multirow[b]{2}{*}{ Total } \\
\hline & $n$ & $\%$ & $n$ & $\%$ & \\
\hline Number & 29 & & 27 & & 56 \\
\hline Mean age (years) & 49 & & 53 & & \\
\hline Gender ( $n$ female) & 15 & 52 & 15 & 55 & 30 \\
\hline Attended with partner & 6 & 21 & 5 & 19 & 11 \\
\hline \multicolumn{6}{|l|}{ Marital status } \\
\hline Married & 14 & 48 & 15 & 55 & 29 \\
\hline \multicolumn{6}{|l|}{ Significant other } \\
\hline Child & 18 & 62 & 19 & 70 & 37 \\
\hline Partner & 9 & 31 & 7 & 26 & 17 \\
\hline Other & 2 & 7 & 1 & 4 & 3 \\
\hline \multicolumn{6}{|l|}{ Ethnicity } \\
\hline White British/European & 22 & 76 & 20 & 74 & 44 \\
\hline \multicolumn{6}{|l|}{ Black African/ } \\
\hline Afro-Caribbean & 4 & 14 & 3 & 11 & 7 \\
\hline Other & 3 & 10 & 4 & 15 & 7 \\
\hline
\end{tabular}


Table 2

Estimated Marginal Means of Weekly Incidents Recorded by Family Members in the Immediate-Treatment and Delayed-Treatment Groups

\begin{tabular}{|c|c|c|c|c|c|c|c|c|}
\hline & \multicolumn{2}{|c|}{ Delayed treatment } & \multicolumn{2}{|c|}{ Immediate treatment } & \multirow{2}{*}{$\begin{array}{c}\text { Difference } \\
\text { Estimate }\end{array}$} & \multirow[b]{2}{*}{$95 \% \mathrm{CI}$} & \multirow[b]{2}{*}{$z$-value } & \multirow[b]{2}{*}{$p$} \\
\hline & $M(\mathbf{n})$ & $\overline{\mathrm{SE}}$ & $M(\mathbf{n})$ & $\overline{S E}$ & & & & \\
\hline Baseline & $3.85(27)$ & 0.32 & $4.28(29)$ & 0.30 & 0.42 & $-0.44,1.28$ & 0.97 & .334 \\
\hline Phase 1 & $3.86(26)$ & 0.26 & $3.22(29)$ & 0.25 & -0.64 & $-1.34,0.07$ & -1.77 & .076 \\
\hline Phase 2 & $3.86(27)$ & 0.25 & $2.16(29)$ & 0.25 & -1.70 & $-2.38,-1.01$ & -4.85 & $<.000$ \\
\hline Follow-up & $3.86(25)$ & 0.29 & $1.11(21)$ & 0.30 & -2.75 & $-3.57,-1.94$ & -6.62 & $<.000$ \\
\hline
\end{tabular}


Table 3

Estimated Marginal Means (SD) for Self-Report Questionnaire Measures

\begin{tabular}{|c|c|c|c|c|c|c|c|c|c|c|c|c|}
\hline \multirow[b]{2}{*}{ Time } & \multicolumn{2}{|c|}{ BDI } & \multicolumn{2}{|c|}{ STAI Total } & \multicolumn{2}{|c|}{ BAS } & \multicolumn{2}{|c|}{ WEMWBS } & \multicolumn{2}{|c|}{ SCORE-15 } & \multicolumn{2}{|c|}{ FES } \\
\hline & IIG & DIG & IIG & DIG & IIG & DIG & IIG & DIG & IIG & DIG & IIG & DIG \\
\hline Baseline & $\begin{array}{l}16.63 \\
(1.66)\end{array}$ & $\begin{array}{l}16.76 \\
(1.64)\end{array}$ & $\begin{array}{l}46.21 \\
(1.89)\end{array}$ & $\begin{array}{l}46.85 \\
(1.95)\end{array}$ & $\begin{array}{l}59.63 \\
(2.52)\end{array}$ & $\begin{array}{l}58.27 \\
(2.48)\end{array}$ & $\begin{array}{l}42.86 \\
(1.48)\end{array}$ & $\begin{array}{l}41.51 \\
(1.51)\end{array}$ & $\begin{array}{l}37.14 \\
(1.70)\end{array}$ & $\begin{array}{l}40.56 \\
(1.76)\end{array}$ & $\begin{array}{l}57.22 \\
(2.95)\end{array}$ & $\begin{array}{l}61.04 \\
(3.12)\end{array}$ \\
\hline 1 & $\begin{array}{l}14.93 \\
(1.46)\end{array}$ & $\begin{array}{l}15.79 \\
(1.49)\end{array}$ & $\begin{array}{l}45.71 \\
(1.92)\end{array}$ & $\begin{array}{l}47.26 \\
(2.01)\end{array}$ & $\begin{array}{l}55.35 \\
(2.16)\end{array}$ & $\begin{array}{l}54.91 \\
(2.17)\end{array}$ & $\begin{array}{l}43.29 \\
(1.50)\end{array}$ & $\begin{array}{l}41.06 \\
(1.56)\end{array}$ & $\begin{array}{l}36.19 \\
(1.60)\end{array}$ & $\begin{array}{l}40.82 \\
(1.68)\end{array}$ & $\begin{array}{l}58.60 \\
(2.95)\end{array}$ & $\begin{array}{l}60.22 \\
(3.14)\end{array}$ \\
\hline 2 & $\begin{array}{l}13.21 \\
(1.37)\end{array}$ & $\begin{array}{l}14.82 \\
(1.43)\end{array}$ & $\begin{array}{l}45.22 \\
(1.99)\end{array}$ & $\begin{array}{l}47.67 \\
(2.09)\end{array}$ & $\begin{array}{l}51.07 \\
(1.98)\end{array}$ & $\begin{array}{l}51.55 \\
(2.05)\end{array}$ & $\begin{array}{l}43.72 \\
(1.57)\end{array}$ & $\begin{array}{l}40.62 \\
(1.64)\end{array}$ & $\begin{array}{c}35.24 \\
(1.56)^{*}\end{array}$ & $\begin{array}{l}41.07 \\
(1.66)\end{array}$ & $\begin{array}{l}59.98 \\
(2.98)\end{array}$ & $\begin{array}{l}59.39 \\
(3.19)\end{array}$ \\
\hline 3 & $\begin{array}{l}11.51 \\
(1.38)\end{array}$ & $\begin{array}{l}13.85 \\
(1.48)\end{array}$ & $\begin{array}{l}44.73 \\
(2.09)\end{array}$ & $\begin{array}{l}48.08 \\
(2.21)\end{array}$ & $\begin{array}{l}46.79 \\
(2.03)\end{array}$ & $\begin{array}{l}48.19 \\
(2.14)\end{array}$ & $\begin{array}{l}44.16 \\
(1.67)\end{array}$ & $\begin{array}{l}40.17 \\
(1.76)\end{array}$ & $\begin{array}{c}34.29 \\
(1.58)^{*}\end{array}$ & $\begin{array}{l}41.33 \\
(1.70)\end{array}$ & $\begin{array}{l}61.36 \\
(3.05)\end{array}$ & $\begin{array}{l}58.56 \\
(3.27)\end{array}$ \\
\hline 4 & $\begin{array}{c}9.80 \\
(1.51)\end{array}$ & $\begin{array}{l}12.88 \\
(1.62)\end{array}$ & $\begin{array}{l}44.23 \\
(2.22)\end{array}$ & $\begin{array}{l}48.49 \\
(2.35)\end{array}$ & $\begin{array}{l}42.52 \\
(2.29)\end{array}$ & $\begin{array}{l}44.83 \\
(2.41)\end{array}$ & $\begin{array}{l}44.59 \\
(1.81)\end{array}$ & $\begin{array}{l}39.73 \\
(1.92)\end{array}$ & $\begin{array}{c}33.34 \\
(1.66)^{* *}\end{array}$ & $\begin{array}{l}41.58 \\
(1.80)\end{array}$ & $\begin{array}{l}62.74 \\
(3.15)\end{array}$ & $\begin{array}{l}57.74 \\
(3.37)\end{array}$ \\
\hline 5 & $\begin{array}{c}8.09 \\
(1.73)\end{array}$ & $\begin{array}{l}11.91 \\
(1.84)\end{array}$ & $\begin{array}{l}43.74 \\
(2.37)\end{array}$ & $\begin{array}{l}48.90 \\
(2.51)\end{array}$ & $\begin{array}{l}38.24 \\
(2.70)\end{array}$ & $\begin{array}{l}41.48 \\
(2.82)\end{array}$ & $\begin{array}{c}45.02 \\
(1.97)^{* * *}\end{array}$ & $\begin{array}{l}39.28 \\
(2.09)\end{array}$ & $\begin{array}{c}32.39 \\
(1.78)^{* * *}\end{array}$ & $\begin{array}{l}41.84 \\
(1.94)\end{array}$ & $\begin{array}{l}64.12 \\
(3.27)\end{array}$ & $\begin{array}{l}56.91 \\
(3.51)\end{array}$ \\
\hline Follow-up & $\begin{array}{c}6.39 \\
(2.01)\end{array}$ & $\begin{array}{l}10.94 \\
(2.11)\end{array}$ & $\begin{array}{l}43.25 \\
(2.54)\end{array}$ & $\begin{array}{l}49.31 \\
(2.69)\end{array}$ & $\begin{array}{l}33.96 \\
(3.20)\end{array}$ & $\begin{array}{l}38.12 \\
(3.32)\end{array}$ & $\begin{array}{c}45.46 \\
(2.15)^{* *}\end{array}$ & $\begin{array}{l}38.84 \\
(2.28)\end{array}$ & $\begin{array}{c}31.44 \\
(1.96)^{* * * *}\end{array}$ & $\begin{array}{l}42.09 \\
(1.12)\end{array}$ & $\begin{array}{c}65.50 \\
(3.42)^{*}\end{array}$ & $\begin{array}{l}56.08 \\
(3.66)\end{array}$ \\
\hline
\end{tabular}

Note. IIG = immediate intervention group; DIG = delayed intervention group; BDI = Beck Depression Inventory; STAI = Spielberger State-Trait Anxiety Inventory; BAS = Burden Assessment Scale; WEMWBS = Warwick-Edinburgh Mental Wellbeing Scale; SCORE-15 = Index of family functioning and change; FES = Family Empowerment Scale.

${ }^{*} p<.05 . * * p<.01 . * * * p<.001$. 
Figure 1. FACTS CONSORT Flow Diagram

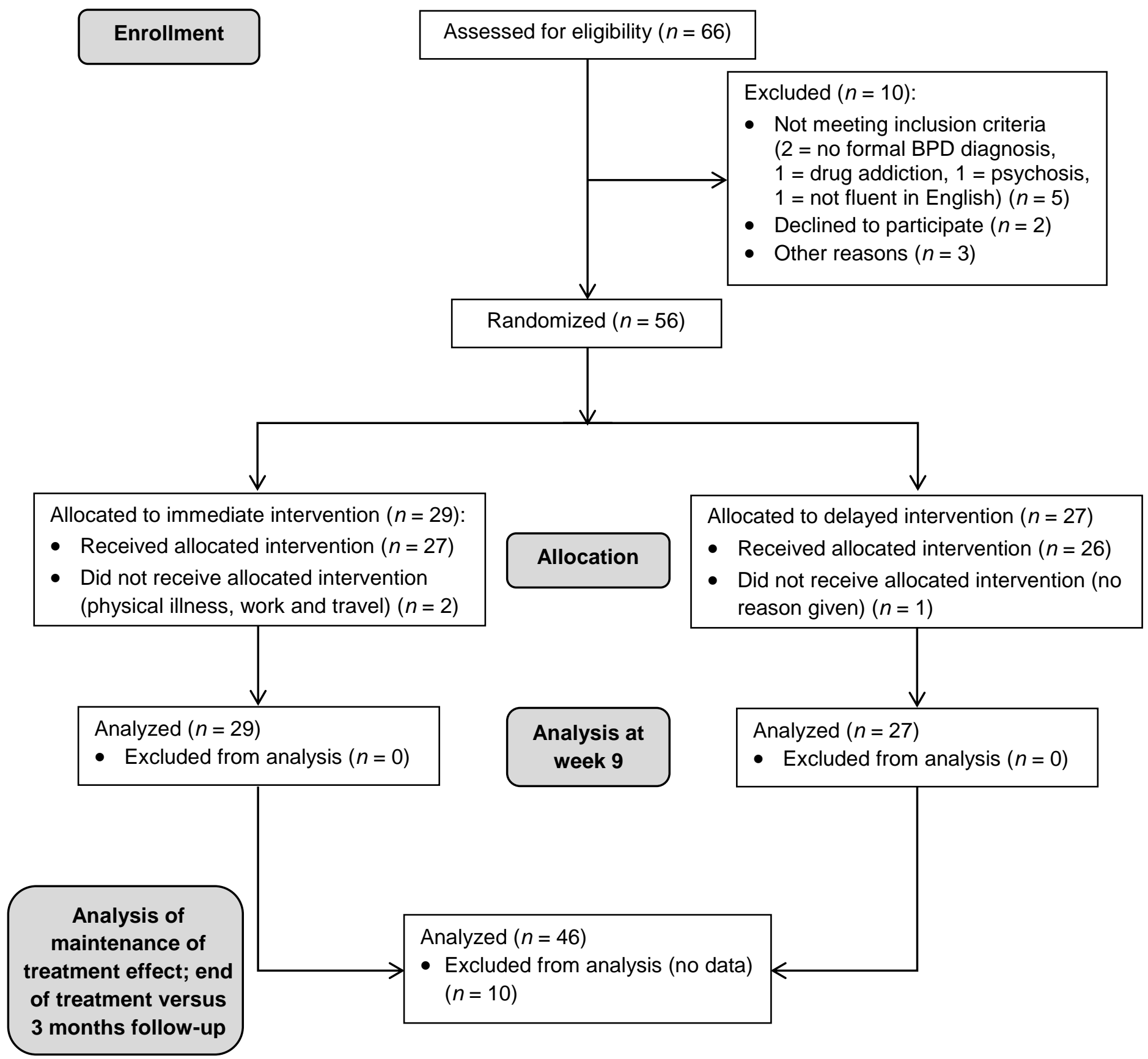


Figure 2. Observed and Predicted Means for Incidents in the Immediate-Treatment and Delayed-Treatment (Control) Groups

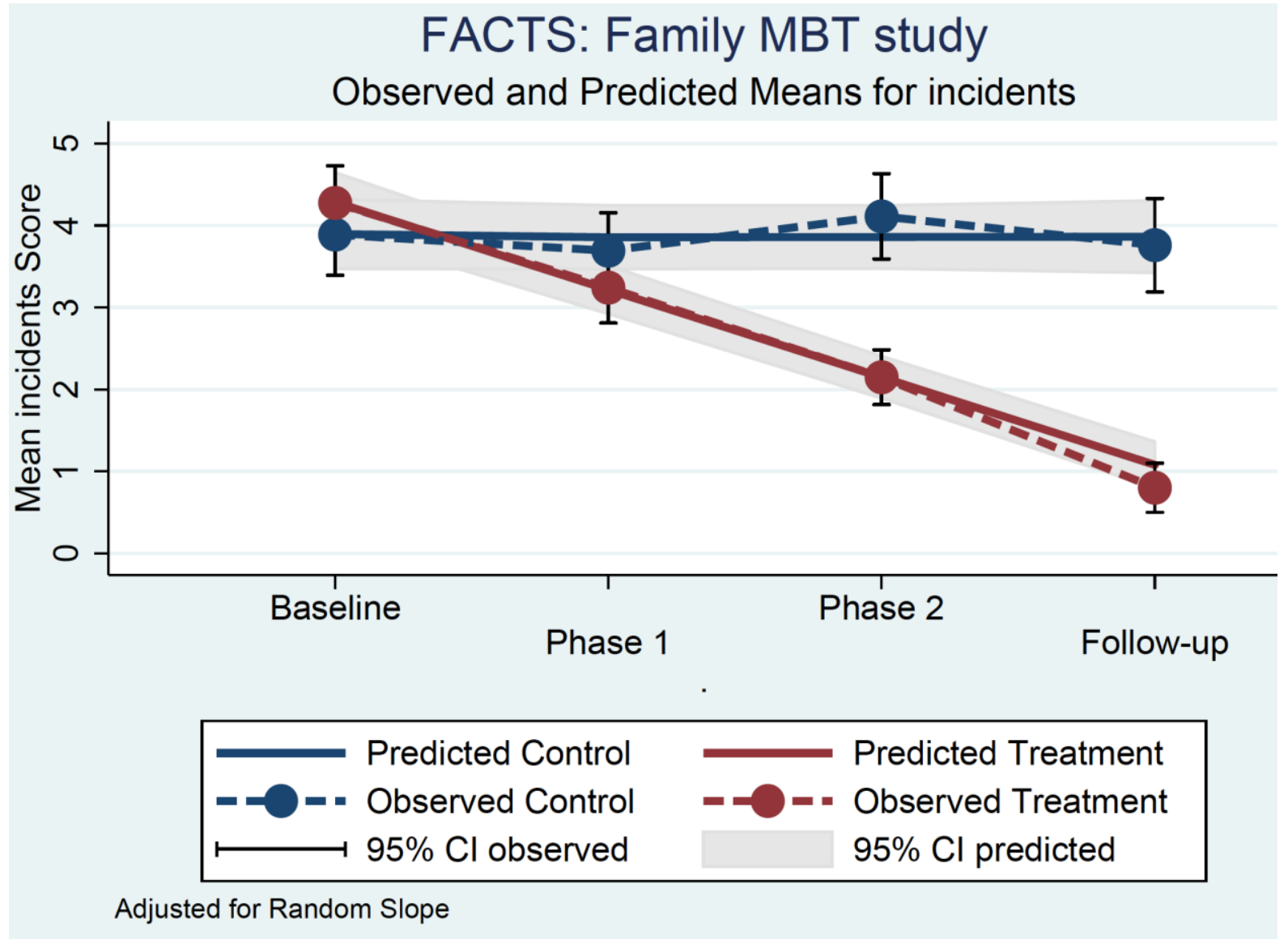

